\title{
O PAPEL DO ASSISTENTE SOCIAL NA CENTRAL DE NOTIFICAÇÃO, CAPTAÇÃO E DISTRIBUIÇÃO DE ÓRGÃOS DA BAHIA
}

\author{
THE ROLE OF THE SOCIAL ASSISTANT AT THE CENTER OF NOTIFICATION, CAPTURE AND \\ DISTRIBUTION OF ORGANS IN BAHIA
}

Sílvia Franco Dórea Bandeira*

\section{RESUMO}

Artigo que trata do desenvolvimento do trabalho de doação/transplante de órgãos e tecidos realizado pela Central de Notificação, Captação e Distribuição de Órgãos da Bahia (CNCDO). Este trabalho objetiva informar e avaliar o ingresso do Assistente Social nesse processo, visando dinamizar o sistema de doação e dar assistência social à coletividade, na área da doação de órgãos.

A metodologia de trabalho do Serviço Social envolve palestras, seminários e contatos corpo-a-corpo com indivíduos durante todo o processo de doação, possibilitando o acesso a informações e viabilizando o esclarecimento do papel do Assistente Social na CNCDO e versando sobre a doação / transplante, cuja tônica é educar o ser humano para uma prática solidária e amorosa, no momento em que se pode salvar uma vida.

Descritores: Doadores de Órgãos; Transplante de Órgãos; Serviço Social; Assistência Social; Vida.

Instituição:

* Central de Notificação, Captação e Distribuição de Órgãos da Bahia (CNCDO) Salvador / BA - Brasil

\section{Correspondência:}

\section{Sílvia Franco Dórea Bandeira}

Secretaria de Saúde do Estado da Bahia - SESAB

Av. Luís Viana Filho, $4^{\mathrm{a}}$ Avenida, Plataforma 6, Iado B, $\mathrm{n}^{\circ} 400,4^{\circ}$ andar, Centro Administrativo da Bahia, Sussuarana - Salvador / BA - CEP: 41745-000 - Brasil

Tels.: (71) 31158316 / 33537822 / 96028867

E-mail: sfdb80@yahoo.com.br

\section{INTRODUÇÃO}

A Coordenação do Sistema Estadual de Transplantes, na Bahia vem caminhando a passos largos e se desenvolve em sua plenitude com o apoio incontestável da atual Administração. O Programa de Transplantes ganha dimensões históricas no Estado e é formatado com a Coordenação integrante da Diretoria de Atenção Especializada, da Superintendência de Atenção Integral à Saúde, da Secretaria da Saúde do Estado da Bahia.

O Sistema Estadual de Transplantes delineia-se como um complexo sistema, que apresentava muitas imperfeições, mas que vem ganhando contornos mais nítidos, com mudanças de toda a ordem e estabelecimento de novos fluxos.

Também integra esse Sistema o Banco de Olhos que funciona dentro da estrutura física do Hospital Geral Roberto Santos (HGRS), armazenando córneas para transplante e cuidando em manter a qualidade daquele tecido, bem como a Central de Notificação, Captação e Distribuição de Órgãos (CNCDO), que permanece utilizando a estrutura física do Hospital Geral do Estado (HGE). Vale lembrar que esses são os maiores hospitais públicos do Estado da Bahia, sendo que o último configura-se como hospital de trauma, apresentando três Unidades de Terapia Intensiva (UTI).

A CNCDO, criada na década de 90, já funcionou durante algum tempo no HGRS - Hospital Geral Roberto Santos, e até o ano de 2005 não vinha apresentando resultados satisfatórios, assim como o Sistema em geral. O índice de doações caía vertiginosamente. $\mathrm{Na}$ atual Coordenação, todo o sistema vem sendo repensado, e estão sendo estabelecidas modificações para otimizar o processo doação / transplante. 
Em junho de 2007, com a nova gestão, toda equipe de Coordenação Estadual deslocou-se para a CNCDO.

No estado da Bahia, além da Central de Transplantes, coube à estrutura da Secretaria da Saúde do estado da Bahia (SESAB) a Coordenação do Sistema Estadual de Transplantes (COSET), que gerencia e regula todo o sistema. Assim sendo, a COSET vem se encarregando da reestruturação da Central de Transplantes em todos os seus aspectos, no que concerne aos recursos humanos, materiais, estabelecimento de fluxos e tomada de decisões no âmbito administrativo.

O trabalho tem sido árduo. Várias modificações e intervenções foram necessárias, visando melhorar o sistema de doação. A inclusão do trabalho do Serviço Social no processo comprova esse objetivo.

A CNCDO apresentava espaço físico reduzido e havia necessidade de implantar rotinas de toda ordem. Algumas mudanças aconteceram na Coordenação da Central de Transplantes, como a contratação de médicos para a busca ativa e profissionais de enfermagem, seleção de estagiários de Medicina e Enfermagem, contratação de psicólogo, cursos de informática, reciclagem no sistema DATASUS para os profissionais administrativos e aquisição de novos motoristas, visando dar agilidade ao processo de doação de órgãos e tecidos, sendo que a COSET assumiu o sistema em sua totalidade.

A Busca Ativa tem na CNCDO uma forte referência, apesar de ser discutido na equipe o envolvimento que a Central de Transplantes ainda tem em ramificações do sistema que ainda não se estruturaram. Isto acontecia, por exemplo, com o Banco de Olhos que, paulatinamente, vem desenvolvendo maior autonomia e independência em suas atribuições.

Pelo fato desse sistema não se encontrar formatado em sua plenitude, a CNCDO ainda se envolvia em rotinas que não eram de sua alçada. Um exemplo disso era a condução de córneas para o Banco de Olhos, feita à época pelo motorista da Central. Atualmente, o Banco de Olhos já assume essa atividade, cuja execução cabe ao plantonista.

\section{BREVE HISTÓRICO SOBRE SERVIÇO SOCIAL}

O Serviço Social, em suas origens, está atrelado à caridade social aos pobres desassistidos. Conforme dispõe Castro ${ }^{1}$ em seus princípios basilares, a profissão sempre esteve vinculada ao Estado e à questão da assistência. Muito ligado à Igreja Católica em suas origens, o Serviço Social apresentava uma práxis assistencialista e, no decorrer do tempo, construiu um viés crítico em relação à realidade vivenciada.

Historicamente, no âmbito profissional, o assistente social vem assumindo uma aliança com as camadas mais desfavorecidas da população e com os movimentos sociais, como afirma Iamamoto: ${ }^{2}$

A especificidade maior que reveste o Serviço Social desde sua implantação [...] historicamente se localiza na demanda social que legitima o empreendimento. Se as Leis Sociais são, em última instância, resultantes da pressão do proletariado pelo reconhecimento de sua cidadania social, o Serviço Social se origina de uma demanda diametralmente oposta. Sua legitimação diz respeito apenas a grupos e frações restritos das classes dominantes em sua origem e, logo em seguida, ao conjunto das classes dominantes. ${ }^{2}$
Diante desse cenário, o estado buscou formas de controle para as manifestações populares, como narra Iamamoto. ${ }^{2}$

A pressão exercida pelo proletariado permanece constantemente como pano de fundo, a partir do qual atores sociais mobilizam políticas diferenciadas. Essas políticas demarcarão os limites dentro dos quais irá surgir e atuar o Serviço Social - a caridade e a repressão - limites em relação aos quais deve se constituir numa alternativa. ${ }^{2}$

O Serviço Social estava estritamente vinculado à Igreja Católica, assumindo uma prática assistencialista e fazendo com que o proletariado se conformasse com sua condição social. Posteriormente, rompeu com a Igreja, passando a delinear-se como profissão enquanto o capitalismo monopolista se consolidou. A partir daí, o estado começou a intervir na questão social por intermédio das políticas sociais públicas, havendo a carência de profissionais para operacionalizar essa intervenção.

Em março de 1967, um movimento estabeleceu o divisor de águas na reconceituação do Serviço Social: o Encontro de Araxá (Minas Gerais), que representou o primeiro Seminário de Teorização do Serviço Social no Brasil. O Documento de Araxá buscou dar uma nova roupagem teórica à metodologia do Serviço Social. A reconceituação do Serviço Social redefiniu todo o seu arcabouço teórico-metodológico, com uma nova perspectiva de enfrentamento da questão social, propiciando aos movimentos sociais (entenda-se classes populares) um instrumento de ação por meio do assistente social.

O Serviço Social, apresenta atualmente um leque de possibilidades no que concerne a sua atuação profissional. O Estado ainda é um grande empregador de profissionais desse porte. A área de saúde destaca-se enquanto pólo empregador, sendo os hospitais, incluindo os psiquiátricos, campos de atuação relevantes da categoria. Dessa maneira, no Judiciário, nas empresas (recursos humanos), na área de educação, na atenção à terceira idade, no atendimento a crianças e adolescentes e, recentemente, na área de transplantes de órgãos e tecidos, encontra-se uma vasta gama de possibilidades de atuação desse profissional.

\section{O SERVIÇO SOCIAL NO SISTEMA DE TRANSPLANTE}

Enquanto a equipe de enfermagem estabelecia fluxos e Procedimentos Operacionais Padrão, a Coordenação Administrativa da Central de Transplantes iniciou a organização do espaço físico e da equipe administrativa, composta por servidores que operavam as listas de espera e acompanhavam à época o status dos usuários e suas equipes.

Posteriormente, foram admitidas por concurso público três assistentes sociais, com as quais se procurou iniciar o que seria a primeira experiência do Serviço Social na CNCDO da Bahia, sendo que duas delas atualmente integram a Comissão Intra-Hospitalar de Doação de Órgãos e Tecidos para Transplantes (CIHDOTT) do Hospital Geral Ernesto Simões Filho em Salvador, instituto que representa significativo papel no sistema, devido ao aumento quantitativo de doações da Unidade.

A equipe de Assistentes Sociais da CNCDO começou a manter contato com hospitais públicos e com toda Rede Própria da Secretaria da Saúde do estado da Bahia (SESAB), e também com as Diretorias Regionais de Saúde (DIRES). Essas Diretorias englobam cada uma de 8 a 22 municípios, dependentes da regional. 
Houve inicialmente uma sensibilização das DIRES, com envio de material informativo para divulgação do Programa de Transplantes em todo o interior do estado. Acompanhávamos também a cada passo no Hospital Geral do estado as rotinas das equipes de Busca Ativa e algumas entrevistas com familiares de potenciais doadores (após o fechamento do protocolo de Morte Encefálica).

Na Central de Transplantes o procedimento de doação e os contatos diários com as equipes na distribuição de órgãos vêm sendo acompanhado. Aos poucos, ao longo de um ano de intervenção no sistema e com a participação de todos os técnicos, a Coordenação do Sistema Estadual de Transplantes vem conseguindo modificar o panorama encontrado, aumentando paulatinamente o quantitativo de doações.

Entre junho e dezembro de 2007 foi dada colaboração à equipe técnica na coordenação das áreas Administrativa e Social. Procurou-se nesse período orientar as assistentes sociais recém-chegadas sobre todo processo que envolve a doação/ transplante, fornecendo-lhes inclusive a legislação pertinente sobre a matéria.

Busca-se principalmente cultivar na equipe o entusiasmo por esse trabalho, que se constitui em um campo novo de atuação para o profissional de Serviço Social, sendo que, nesse período, não existia sequer a presença de estagiários de Serviço Social.

Além das atividades mencionadas, atendia-se a imprensa e estudantes de vários cursos como Medicina, Enfermagem e Jornalismo em busca de dados e material informativo para apresentar trabalhos no meio acadêmico.

Eram atendidos também alguns usuários do sistema, transplantados ou não, em busca das mais variadas informações, tais quais: se o seu nome constava da lista de receptores; onde fazer uma consulta com médico transplantador; qual o encaminhamento para o Tratamento Fora Domicílio (TFD). Ressaltamos que é indescritível a alegria estampada no semblante de quem recebeu esse gesto humanitário e de extrema solidariedade humana, que é a DOAÇÃO DE ÓRGÃOS!

Do ponto de vista pessoal, a doação traduz-se num ato de amor, desapego e solidariedade de um ser para outro. Um indivíduo viabiliza a vida e a saúde do outro, sem conhecê-lo ou tampouco estabelecer qualquer tipo de contato. Em suma, consiste num gesto em que não há contrapartida ou interesse. O vínculo que se forma é solidário e amoroso. Do prisma social, a doação compreende fator de incentivo para que muitos salvem algumas vidas, dinamizando a existência da coletividade.

Trabalhou-se também com eventos, organizando-se palestras e divulgando-se o Programa de Transplantes nas Universidades, empresas, Projeto de Ação Global do SESI e, na Escola Parque, em Salvador quase 300 crianças ouviram atentamente explanações sobre o tema. Este trabalho objetiva familiarizar e educar o futuro adulto com o assunto aqui discutido.

No final de 2007 começou-se a pensar sobre a necessidade de reunir a categoria para falar sobre este assunto, tão pouco conhecido no estado da Bahia, e já em abril de 2008 conseguiu-se realizar o I Seminário sobre a Prática do Serviço Social no Programa Estadual de Transplantes - Novos Desafios - com a participação de cerca de 100 profissionais e lista de espera de mais 70 pessoas interessadas em um próximo evento, o que constituiu-se de uma grata surpresa.

A Coordenação de Transplantes vem agregando mais assistentes sociais ao sistema como um todo, por acreditar no trabalho desses profissionais em virtude de seu vínculo com a questão sócioassistencial. Já existem reuniões e algumas assistentes sociais nas CIHDOTT que ora estão sendo formadas.

Fazendo parte da conformação do Sistema Estadual, a Central de Notificação, Captação e Distribuição de Órgãos é a unidade executiva das atividades do Sistema Nacional de Transplantes (SNT).

A CNCDO não tem recebido notificações de morte encefálica necessárias para desencadear o procedimento de doação de órgãos. Consideramos que as principais dificuldades passam pela falta de cultura em transplantes, ausência de conscientização dos profissionais de saúde e negativa familiar, dentre outras.

Vale ressaltar que a SESAB vem promovendo a aquisição de equipamentos para diagnóstico de Morte Encefálica, como eletroencefalograma (EEG) e o Doppler transcraniano, visando melhor identificar os potenciais doadores.

No tocante ao processo doação/transplante, vale ressaltar a legislação que ampara a criação das Comissões Intra Hospitalares de Doação de Órgãos e Tecidos para Transplantes (CIHDOTT), que são constituídas através de portaria publicada no Diário Oficial do Estado, cuja designação parte da Direção da unidade à qual estão vinculadas. É importante destacar a importância daquele instituto nos hospitais, como uma das formas de promover a conscientização e sensibilização da comunidade em geral, bem como da equipe técnica sobre o processo de doação / transplante e a importância da doação de órgãos e tecidos como uma área da política pública de saúde do país.

A atuação da CIHDOTT também é de suma importância no momento da entrevista familiar, momento em que a família já foi comunicada do óbito pela unidade hospitalar e está sofrendo a perda do seu ente querido. Os membros da CIHDOTT precisam ter habilidade ao lidar com emoções que afloram durante o contato com as famílias em situação de sofrimento.

\section{CONCLUSÃO}

No que se refere ao trabalho desenvolvido pelo Serviço Social, o papel do Assistente Social vem se ampliando no Sistema Estadual de Transplantes, a partir da inclusão de mais profissionais em todas as suas ramificações, extrapolando a prática inicial na CNCDO, atuando na: CIHDOTT, promoção de eventos, articulações com as Universidades, supervisão de estágio, enfim, um diverso leque de possibilidades que envolvem o processo de doação e a possibilidade de promover a vida humana.

\section{AGRADECIMENTOS}

Quero prestar uma justa homenagem a dois senhores que foram exemplos de dignidade e honradez durante suas existências, e partiram desta vida deixando muitas saudades: Milton Brandão Dórea, meu pai, e Naudeck Lopes Bandeira, meu sogro, ambos falecidos recentemente, representando uma perda irreparável para suas famílias. 